\title{
Identification of a Dopamine Transporter Ligand That Blocks the Stimulant Effects of Cocaine
}

\author{
Rajeev I. Desai, ${ }^{1}$ Theresa A. Kopajtic, ${ }^{1}$ Mikhail Koffarnus, ${ }^{1}$ Amy Hauck Newman, ${ }^{2}$ and Jonathan L. Katz ${ }^{1}$ \\ ${ }^{1}$ Psychobiology and ${ }^{2}$ Medicinal Chemistry Sections, Medications Discovery Research Branch, National Institute on Drug Abuse, Intramural Research \\ Program, Department of Health and Human Services, National Institutes of Health, Baltimore, Maryland 21224
}

\begin{abstract}
There is a large unmet medical need for cocaine addiction treatments. Studies have indicated that the dopamine transporter (DAT) is the primary biological target of cocaine, and most drugs that have DAT affinity have behavioral effects like those of cocaine. However, analogs of benztropine have high DAT affinity and behavioral effects that show varying degrees of similarity to cocaine. We now report the discovery that a benztropine analog, JHW007, with high affinity for the DAT does not have cocaine-like behavioral effects and antagonizes the effects of cocaine. JHW007 occupied the DAT in vivo more slowly than did cocaine and had not reached an apparent plateau up to 270 min after injection. The in vivo binding of cocaine to the DAT suggested rate of DAT occupancy as an important contributor to its behavioral effects, and the slow association with the DAT may provide an explanation for JHW007 being relatively devoid of cocaine-like behavioral effects. The antagonism of cocaine suggests that DAT ligands with reduced cocaine-like activity can function as cocaine antagonists and suggests JHW007 as a lead for discovery of cocaine-abuse pharmacotherapeutics.
\end{abstract}

Key words: cocaine abuse; cocaine antagonist; dopamine transporter; ex vivo binding; JHW007; benztropine analogs

\section{Introduction}

Recent (1999-2002) annual estimates of the number of individuals using cocaine range from 2 to 3.2 million in the United States alone (ONDCP, 2001; SAMSA, 2002), which approximates $1 \%$ of the population. This prevalence is comparable with those for attention deficit hyperactivity disorder (Scahill and SchwabStone, 2000) or schizophrenia (Goldner et al., 2002), as two examples of disorders for which there are significant research investments. Although these estimates suggest more than adequate incentive for drug-discovery research, the currently proven treatments for cocaine addiction are exclusively behavioral.

Several studies indicate that the dopamine transporter (DAT) is the biological target for the effects of cocaine underlying its abuse liability. Binding at the DAT interferes with the reuptake of DA, producing an increase in extracellular DA concentrations (Javitch et al., 1984; Madras et al., 1989), and stimulant effects of cocaine are absent in mice lacking the DAT (Giros et al., 1996). Among the cocaine-like uptake inhibitors that also block serotonin and norepinephrine transport, it is affinity for the DAT that

Received Nov. 23, 2004; revised Jan. 7, 2005; accepted Jan. 8, 2005.

This work was supported by the National Institute on Drug Abuse Intramural Research Program (NIDA-IRP). The animals used in this study were cared for in accordance with the guidelines of the National Institutes of Health Animal Care and Use Program and the NIDA-IRP Animal Program, which is fully accredited by the Association for Assessment and Accreditation of Laboratory Animal Care International. Portions of this manuscript were presented at the 2003 Meeting of the American Society for Pharmacology and Experimental Therapeutics. We thank Jianjing Cao and Dawn French for technical support and James E. Barrett, George A. Ricaurte, Barry Hoffer, and James H. Woods for the review of a previous draft of this manuscript. The locomotor activity data were provided by a contract from the NIDA Division of Treatment Research and Development, Cocaine Treatment Discovery Program to the University of North Texas (Michael J. Forster, Principal Investigator).

Correspondence should be addressed to Dr. Jonathan L. Katz, National Institute on Drug Abuse, Intramural Research Program, National Institutes of Health, 5500 Nathan Shock Drive, Baltimore, MD 21224. E-mail: jkatz@intra.nida.nih.gov.

D0I:10.1523/JNEUROSCI.4778-04.2005

Copyright $\odot 2005$ Society for Neuroscience $\quad$ 0270-6474/05/251889-05\$15.00/0 correlates with potency in preclinical models of drug abuse $(\mathrm{Ku}-$ har et al., 1991), supporting the hypothesis that blockade of DA transport is the mechanism underlying the abuse liability of cocaine.

There are, however, some DA uptake inhibitors that do not share all of the behavioral effects of cocaine. Analogs of benztropine (BZT), for instance, have high affinity for the DAT and inhibit DA uptake in vitro. However, these drugs compared with cocaine have reduced effectiveness as behavioral stimulants and generally do not share subjective and reinforcing effects of cocaine in drug-discrimination and self-administration animal models (Newman et al., 1995; Katz et al., 1999; Woolverton et al., 2001). These findings suggest that some structural variants of drugs acting at the DAT may have reduced abuse liability compared with cocaine and a potential approach to the discovery of medications for cocaine abuse.

Previous studies of DA uptake inhibitors have indicated that DAT occupancy seems to be an important determinant of the cocaine-like behavioral effects of DA uptake inhibitors (Gatley et al., 1999). However, others have indicated that DAT occupancy is not related to behavioral activity in a simple way (Rothman et al., 1992; Vaugeois et al., 1993). To further study potential mechanisms for differences between cocaine and BZT analogs, we compared the in vivo binding to the DAT of cocaine and an analog of BZT, JHW007 (Agoston et al., 1997), and related those effects to behavioral activity. In the process, we found that JHW007 had in vivo affinity for the DAT and could antagonize the effects of cocaine, which are unprecedented findings among DAT ligands.

\section{Materials and Methods}

Subjects. Male Swiss-Webster mice (Taconic, Germantown, NY), weighing $25-40 \mathrm{~g}$, were kept in a colony maintained at $21 \pm 1^{\circ} \mathrm{C}$ under a $12 \mathrm{~h}$ 
light/dark cycle (lights on 7:00 A.M.). Experiments were conducted between 8:00 A.M. and 3:00 P.M., in a separate room.

Drugs. The drugs used in the present studies were as follows: (-)cocaine hydrochloride (Sigma/Aldrich, St. Louis, MO), JHW007, $\mathrm{N}$-(nbutyl)-(bis-fluorophenyl)methoxytropane, AHN2005, N-allyl-(bisfluorophenyl)methoxytropane (Agoston et al., 1997), and [ $\left.{ }^{125} \mathrm{I}\right] \mathrm{RTI}-121$ (specific activity, $2200 \mathrm{Ci} / \mathrm{mmol}$; PerkinElmer Life Sciences, Boston, MA). All drug solutions were prepared fresh daily in sterile water (cocaine was dissolved in $0.9 \% \mathrm{NaCl}$ ). For in vivo studies, cocaine, JHW007, and AHN2005 were administered by the intraperitoneal route. $\left[{ }^{125} \mathrm{I}\right] \mathrm{RTI}-121$ was administered intravenously in $0.2 \mathrm{ml}$ of sterile water.

$\left[{ }^{3} \mathrm{H}\right]$ Dopamine uptake inhibition. Fresh rat striatum was homogenized in ice-cold buffer ( $5 \mathrm{~mm}$ HEPES and $0.32 \mathrm{~m}$ sucrose), using 10 strokes with a Teflon glass homogenizer before centrifugation $(1000 \times g$ for 10 $\min$ at $\left.4^{\circ} \mathrm{C}\right)$. The supernatant was recentrifuged $(10,000 \times g$ for $10 \mathrm{~min}$ at $4^{\circ} \mathrm{C}$ ), and the pellet was resuspended in ice-cold incubation buffer (in mM: $127 \mathrm{NaCl}, 5 \mathrm{KCl}, 1.3 \mathrm{NaH}_{2} \mathrm{PO}_{4}, 1.2 \mathrm{MgSO}_{4}, 2.5 \mathrm{CaCl}_{2}, 1.498$ HEPES acid, $10 \mathrm{D}$-glucose, and $1.14 \mathrm{~L}$-ascorbic acid, $\mathrm{pH}$ 7.4) and placed on ice for $15 \mathrm{~min}$.

The synaptosomal tissue preparation was incubated in buffer at $37^{\circ} \mathrm{C}$ with $10 \mu \mathrm{M}$ pargyline and JHW007. After $10 \mathrm{~min},\left[{ }^{3} \mathrm{H}\right]$ dopamine $(0.5$ $\mathrm{nM}$ ) was added to each tube. After $5 \mathrm{~min}$, the incubation was terminated by the addition of $3 \mathrm{ml}$ of ice-cold buffer and rapid filtration through Whatman GF/B glass-fiber paper (presoaked in $0.1 \%$ polyethylenimine; Whatman, Clifton, NJ) using a cell harvester (Brandel, Gaithersburg, $\mathrm{MD})$. Filters were then washed $(3 \mathrm{ml})$ twice and transferred to scintillation vials, scintillation fluid $(3 \mathrm{ml})$ was added, and the vials were left overnight. Radioactivity in the presence of $100 \mu \mathrm{M}(-)$-cocaine $\mathrm{HCl}$ was subtracted to determine specific uptake.

Locomotor activity. Mice were tested individually in acrylic chambers $\left(40 \mathrm{~cm}^{3}\right)$ equipped with light-sensitive detectors and corresponding infrared lights spaced $2.5 \mathrm{~cm}$ apart (Omnitech Electronics, Columbus, $\mathrm{OH})$. Each light-beam interruption registered one horizontal activity count. Each dose or dose combination was injected intraperitoneally $(n=8)$, and mice were used once. Mice were given injections and immediately placed in the apparatus for $8 \mathrm{~h}$, with activity counted every 10 min. For antagonism studies, JHW007, AHN2005 (10 mg/kg each), or vehicle was injected immediately before subjects were placed in the chamber, and saline or cocaine $(5-60 \mathrm{mg} / \mathrm{kg}$ ) was administered $270 \mathrm{~min}$ (JHW007) or $210 \mathrm{~min}$ (AHN2005) later, with these times based on maximum in vivo DAT occupancy (our unpublished data). Activity was monitored for an additional $90 \mathrm{~min}$.

Ex vivo binding of $\left[{ }^{125} \mathrm{I}\right] R T I-121$. Displacement of $\left[{ }^{125} \mathrm{I}\right] \mathrm{RTI}-121$ binding by cocaine $(10-40 \mathrm{mg} / \mathrm{kg})$, JHW007 (1-17 mg/kg), or vehicle was examined according to the methods of Scheffel et al. (1989). Subjects $(n=10)$ received $2 \mu \mathrm{Ci}$ of $\left[{ }^{125} \mathrm{I}\right] \mathrm{RTI}-121$ in $0.2 \mathrm{ml}$ of sterile water intravenously and were killed by cervical dislocation $2 \mathrm{~h}$ later. Intraperitoneal injections of vehicle or a displacer were administered at various times before the subjects were killed. When the subjects were killed, whole brains were removed rapidly; the striatum and cerebellum were dissected on ice, placed into separate plastic vials (Rohren Tubes; $55 \times 12$ $\mathrm{mm}$ ), and weighed; and tissue radioactivity was measured (gamma counter; ICN Biomedicals, Huntsville, AL).

Cocaine discrimination. Mice were trained in two-lever operantconditioning chambers (Med Associates, St. Albans, VT) with food reinforcement $(20 \mathrm{mg}$ pellets) to press one lever after cocaine injection and a second lever after saline injection. Lever presses were reinforced under a 10-response fixed-ratio (FR10) schedule.

Mice were placed inside the experimental chambers immediately after injection. The chamber was illuminated $5 \mathrm{~min}$ later, and responses on the appropriate lever were reinforced. Responses on the inappropriate lever reset the FR requirement. Sessions terminated after 20 food presentations or $15 \mathrm{~min}$, whichever occurred first. Daily training sessions with cocaine and saline followed a mixed sequence.

Testing began when criteria were met of $>85 \%$ of responses (over the session, and on the first FR) on the appropriate lever for four consecutive sessions. Substitution tests were conducted with different combinations of doses administered before sessions and two successive sessions of criterion performance between tests. For some tests, 10 mg/kg JHW007 was

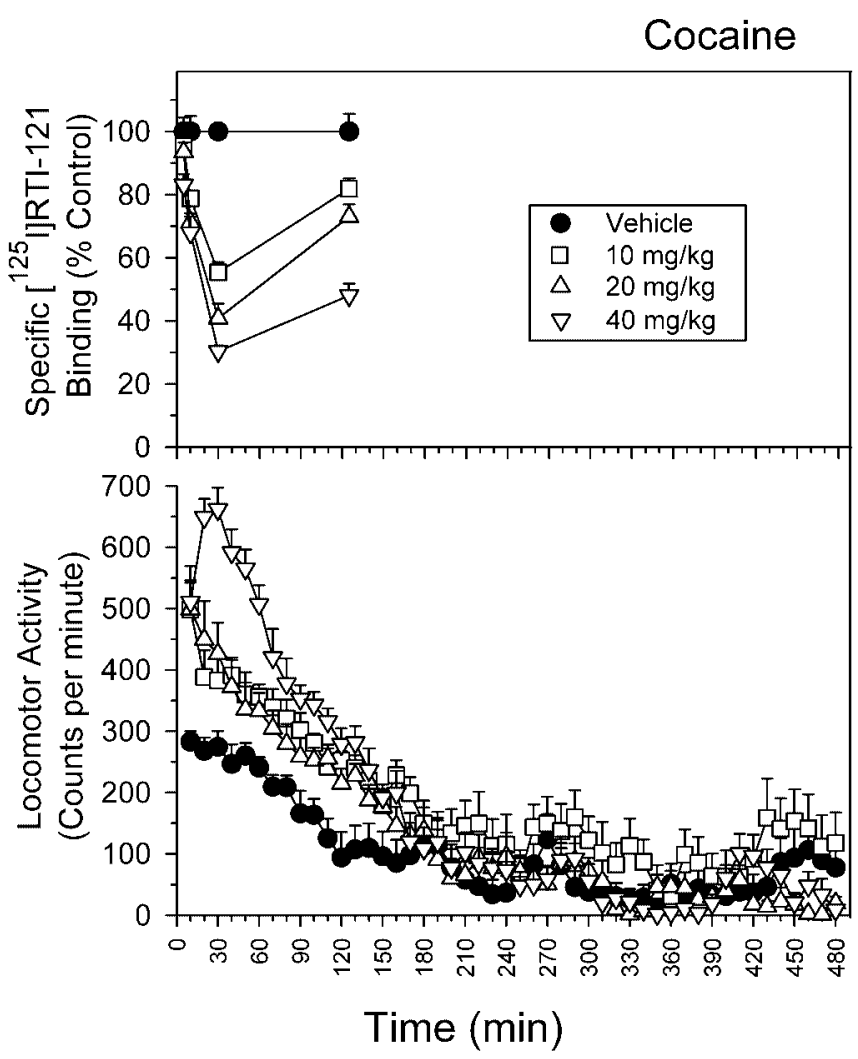

Figure 1. Time course of effects of cocaine on specific [ $\left.{ }^{125} \mathrm{I}\right] \mathrm{RTI}-121$ binding (top) and locomotor activity in mice. $x$-axis, Time after cocaine injection; $y$-axis (top), specific [ ${ }^{125}$ ]]RTI-121 binding expressed as a percentage of vehicle control; $y$-axis (bottom), horizontal activity counts per minute. Each point represents data from 5-13 (top) or 8 (bottom) mice, with error bars representing +1 SEM.

administered at 270 min before cocaine. Test sessions were identical to training sessions, except that responding on either lever was reinforced.

Analysis of data. For ex vivo binding data, regional radioactivity levels (counts per minute) were divided by tissue weight, and a percentage of injected [ ${ }^{125}$ I] RTI-121 dose per kilogram of body weight for each tissue was obtained. Estimates of specific-to-nonspecific binding were obtained [(striatum/cerebellum $)-1]$ based on the observation that DAT sites are highly concentrated in the striatum and relatively absent in the cerebellum (Scheffel et al., 1989). Specific binding after cocaine or JHW007 injection was expressed as a percentage of that obtained after vehicle injection. The displacement data and locomotor activity data were analyzed using two-way ANOVA and post hoc Tukey's tests. Dose-effect curves were analyzed using linear regression techniques to determine $\mathrm{ED}_{50}$ values and their $95 \%$ confidence limits $(\mathrm{CL})$. The percentage of DAT occupancy was calculated by subtracting the percentage of occupancy produced by each drug from that produced by the vehicle. Stimulation of locomotor activity during the \pm 10 min surrounding times at which binding was determined was calculated by subtracting the total counts after vehicle from the total counts after drug. The Pearson's product-moment correlation coefficient of these values was calculated.

\section{Results}

Among the concentrations examined, maximum displacement of $\left[{ }^{125} \mathrm{I}\right] \mathrm{RTI}-121$ was obtained at $40 \mathrm{mg} / \mathrm{kg}$ cocaine at $30 \mathrm{~min}$ after injection. Less displacement was obtained at other times and doses (Fig. 1, top). Cocaine increased locomotor activity in mice in a dose- and time-dependent manner (Fig. 1, bottom) (10-40 $\mathrm{mg} / \mathrm{kg}$ ), with a maximum during the first $30 \mathrm{~min}$. After this time, the amount of activity decreased progressively, reaching control levels at $\sim 170$ min after injection.

The cocaine-induced stimulation of activity was generally in 


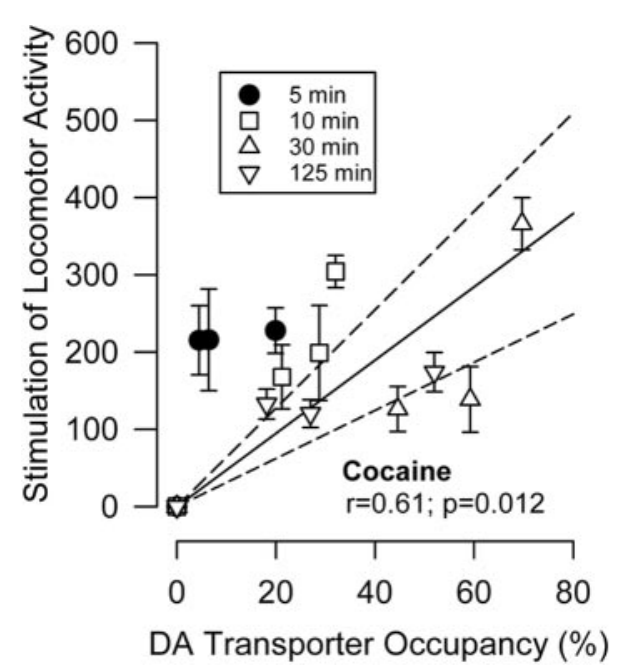

Figure 2. Relationship between occupancy of the DAT in the striatum by cocaine and its locomotor stimulant effects. $y$-axis, The amount of stimulation of horizontal locomotor activity expressed as counts after drug administration minus counts after vehicle administration; $x$-axis, DAT occupancy produced by cocaine (the inverse of specific [ ${ }^{125} \mid \mathrm{RTI}-121$ binding) expressed as a percentage of vehicle controls. The solid line represents the regression of stimulation of locomotor activity on the occupancy of the DAT with the line forced through the origin. The dashed lines represent the $95 \%$ confidence limits for the regression line. The error bars on points represent +1 SEM.

agreement with in vivo DAT occupancy (Fig. 2), and the correlation was significant $(r=0.61 ; p=0.012)$. However, given the established relationship between DAT actions and behavioral effects (Kuhar et al., 1991), the correlation was poor, indicating that occupancy is only one determinant of these behavioral effects of cocaine. Figure 2 indicates that there was greater stimulation than predicted by DAT occupancy at 5 min after injection (filled circles). That this divergence occurred immediately after injection suggests that rate of occupancy also influences the behavioral effects of cocaine.

The BZT analog JHW007 had a relatively high DAT affinity $(23.3 \mathrm{~nm})$ (Agoston et al., 1997) and inhibited DA uptake $\left(\mathrm{IC}_{50}=\right.$ $24.6 \pm 1.97 \mathrm{nM})$. The ex vivo displacement of $\left[{ }^{125} \mathrm{I}\right] \mathrm{RTI}-121$ by JHW007 was dose related, with no plateau apparent at $270 \mathrm{~min}$ after injection (Fig. 3, top). In contrast to cocaine, JHW007 had a slow in vivo apparent association with the DAT; displacement of $\left[{ }^{125} \mathrm{I}\right] \mathrm{RTI}-121$ by $17 \mathrm{mg} / \mathrm{kg} \mathrm{JHW007}$ occurred at a rate of 0.20 $\pm 0.02 \% / \mathrm{min}$, which was significantly $\left(F_{(1,76)}=39.67 ; p<\right.$ $0.0001)$ less than the $2.04 \pm 0.20 \% / \mathrm{min}(5-30 \mathrm{~min})$ obtained with $40 \mathrm{mg} / \mathrm{kg}$ cocaine.

At doses from 1-10 mg/kg, JHW007 failed to produce a significant stimulation of locomotor activity throughout the $8 \mathrm{~h}$ observation period (Fig. 3, bottom) $\left(F_{(3,28)}=1.25 ; p>0.05\right)$. The correlation of the stimulant effects and DAT occupancy of various doses and times after injection of JHW007 was not significant $(r=0.002 ; p=0.995)$. Thus, JHW007 did not show a relationship between the DAT occupancy and behavioral stimulation like that observed with cocaine.

At 270 min after vehicle injection, cocaine produced a doserelated increase in activity, with a maximum at $40 \mathrm{mg} / \mathrm{kg}$. The 60 $\mathrm{mg} / \mathrm{kg}$ cocaine dose increased activity to a lesser extent (Fig. $4 \mathrm{~A}$, circles). Pretreatment with JHW007 (10 mg/kg) completely antagonized the effects of cocaine $\left(F_{(1,82)}=41.953 ; p<0.001\right)$ (Fig. $4 A$, squares). JHW007 alone had no significant effects on activity (Fig. 4A, square). A second experiment confirmed these findings with a different shipment of mice (unconnected points at 40

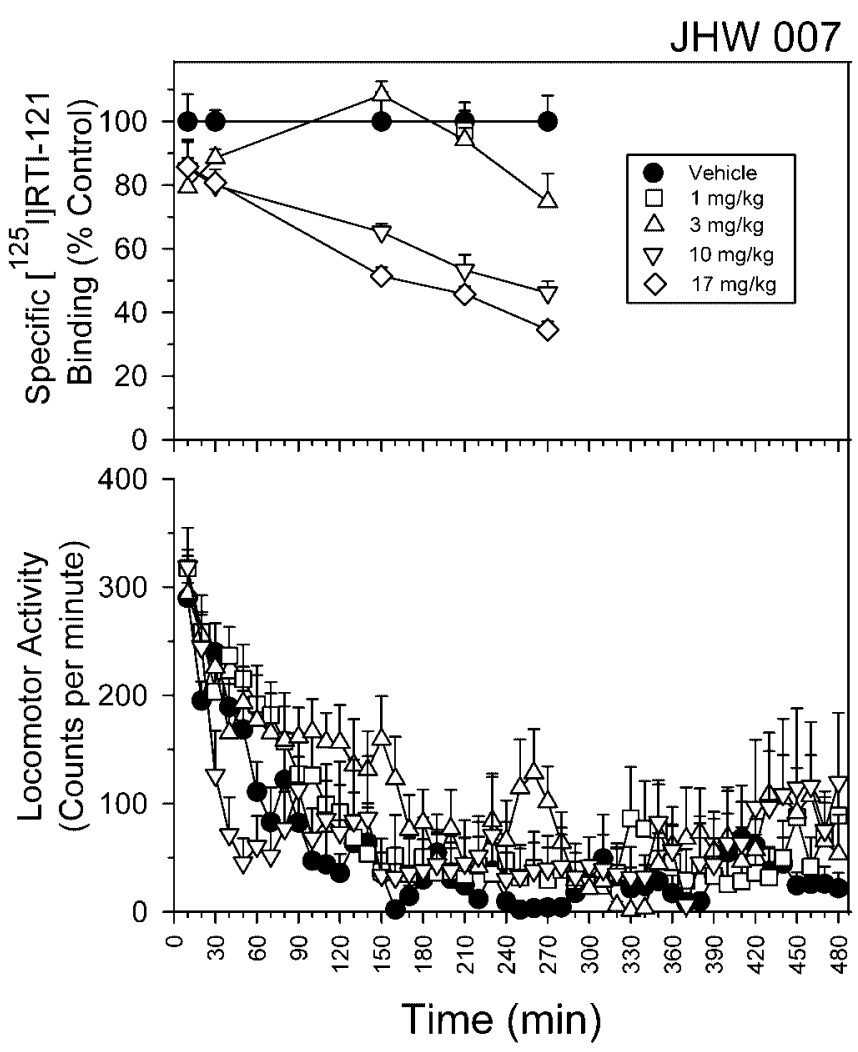

Figure 3. Time course of effects of JHW007 on specific [ $\left.{ }^{125}\right]$ RTI-121 binding (top) and on locomotor activity in mice. $x$-axis, Time after JHW007 injection. Details are as in Figure 1, except binding data are from 5-10 mice (top).

$\mathrm{mg} / \mathrm{kg}$ ). In contrast, the $\mathrm{N}$-allyl derivative of JHW007, AHN2005 $(10 \mathrm{mg} / \mathrm{kg})$, did not antagonize the effects of cocaine $\left(F_{(1,84)}=\right.$ $0.426 ; p>0.05$ ) (Fig. $4 B$, compare diamonds, circles), although there was a decrease in the effects of the highest doses of cocaine.

In cocaine discrimination, there was a dose-related increase in the percentage of responses emitted on the cocaine-appropriate lever, approximating $100 \%$ at the training dose $\left(\mathrm{ED}_{50}=3.31\right.$ $\mathrm{mg} / \mathrm{kg} ; 95 \% \mathrm{CL}=2.39-4.59$ ) (Fig. 4C). JHW007 shifted the cocaine dose-effect curve 3.07 -fold $(95 \% \mathrm{CL}=2.00-4.86)$ to the right, suggestive of a competitive antagonism. The following day (28.5 $\mathrm{h}$ after injection) (Fig. $4 C$, inverted triangle), the antagonist effects of JHW007 were absent.

\section{Discussion}

The DAT is considered the biological target responsible for the abuse liability of cocaine (Kuhar et al., 1991). Consequently, DAT ligands have been examined as potential cocaine-abuse treatments that have high affinity, selectivity, and, to decrease their own abuse liability, slow CNS penetration. Despite substantial effort, a compound that can function as a cocaine antagonist or substantially attenuate the behavioral effects of cocaine has not been reported. The fundamental obstacle has been that compounds that bind to the DAT most often have pharmacologies similar to cocaine. However, previous studies demonstrated that among analogs of BZT are compounds with affinity at the DAT and different magnitudes of cocaine-like effectiveness in behavioral assays (Agoston et al., 1997; Katz et al., 2004). These findings suggest that altering the chemical structure of drugs acting at the DAT may reduce intrinsic cocaine-like effects.

The present data show that JHW007 has a high in vivo affinity for the DAT. The time course for in vivo displacement revealed a 
slower apparent association for JHW007 compared with cocaine. A previous pharmacokinetic comparison of cocaine and JHW007 in rats indicated that both compounds are highly permeable and detectable in the brain minutes after injection (Raje et al., 2003). Together, these studies demonstrate that JHW007 passes the blood-brain barrier and readily penetrates the brain, slowly achieving significant levels of in vivo DAT occupancy. Interestingly, JHW007 failed to produce appreciable cocaine-like locomotor stimulant effects, despite significant in vivo occupancy, consistent with previous studies indicating decreased efficacy of BZT analogs compared with cocaine (Katz et al., 1999, 2001; Woolverton et al., 2001).

Several studies have indicated a strong relationship between DAT binding and behavior for cocaine and other DA uptake inhibitors (Ritz et al., 1987; Bergman et al., 1989; Kuhar et al., 1991; Cline et al., 1992). However, in the present study, a given level of DAT occupancy by cocaine and JHW007 did not produce comparable behavioral effects. These findings indicate that the relationship between binding events at the DAT and behavioral effects may depend on several factors, including the compound being studied. Indeed, differences in chemical structure can lead to DAT inhibitors with different behavioral profiles, as illustrated by the present results with AHN2005. Several other studies have also reported complexities in the relationship between binding and the behavioral effects of DA uptake inhibitors. For example, Rothman et al. (1992) demonstrated in rats that comparable levels of locomotor stimulation were produced by several DA uptake inhibitors, but at different levels of DAT occupancy. Similar findings by Vaugeois et al. (1993), along with the present results, indicate that transduction of pharmacological actions from binding events at the DAT may involve intermediary steps that are modulated by the intrinsic nature of the ligand.

In the present study, the apparent association rate seemed to be a critical difference between JHW007 and cocaine. Immediately after injection the effects of cocaine were greater than that predicted solely by DAT occupancy. The 10-fold slower rate in vivo of DAT occupancy for JHW007 was accompanied by little or no locomotor stimulation. That cocaine-like behavioral effects are related to the rate of DAT occupancy is consistent with a recent report by Volkow et al. (2002) that concluded that rate of DAT occupancy plays a critical role in the subjective response to cocaine in human subjects.

The rate of DAT occupancy alone cannot account for all of the present effects. Pharmacokinetic studies of JHW007 indicate that levels in the brain decline slowly within $30 \mathrm{~min}$ after injection, making the continued slow decrease in $\left[{ }^{125} \mathrm{I}\right] \mathrm{RTI}-121$ binding counter intuitive. A reconciliation of these results might be obtained by examining the effects of JHW007 on the number of DAT sites available for $\left[{ }^{125}\right.$ I]RTI-121 binding. Regulation of DAT membrane surface expression levels has been demonstrated (Blakely and Bauman, 2000), and that some drugs can regulate this expression suggests a potential mechanism for the present effects of JHW007.

It is also possible that JHW007 acts at sites other than the DAT, and those sites may contribute to its unique activity. We
Vehicle + Cocaine JHW007 + Cocaine Vehicle + Cocaine

\section{$\triangle \quad \mathrm{JHW} 007+$ Cocaine \\ $\diamond$ AHN2005 + Cocaine \\ $\nabla$ JHW007 + Cocaine}

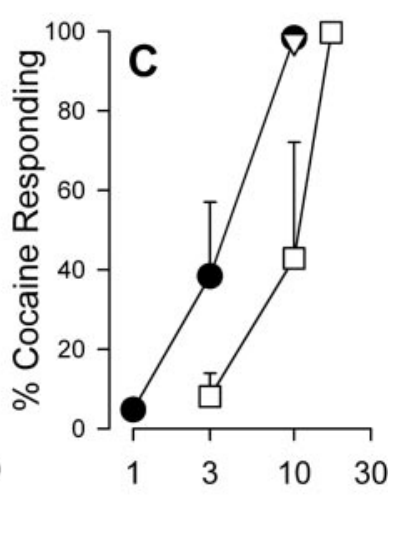

Cocaine $(\mathrm{mg} / \mathrm{kg})$

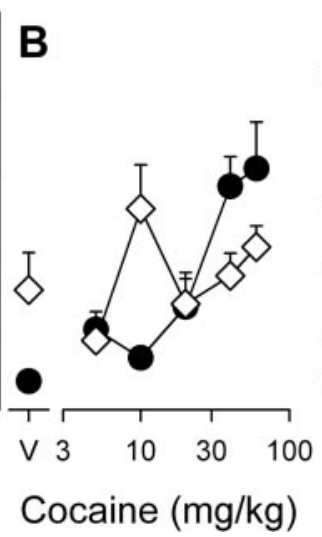

activity counts; $x$-axis, treatment condition, vehicle $(V)$, or dose of cocaine. Each point represents the average effect determined in eight mice, except $n=6$ for combination of 10 $\mathrm{mg} / \mathrm{kg}$ JHW007 plus $60 \mathrm{mg} / \mathrm{kg}$ cocaine. The unconnected points above $40 \mathrm{mg} / \mathrm{kg}$ cocaine show a replicate determined several months later in a separate shipment of mice. $C, y$-axis, Percentage of responses on the cocaine-appropriate lever after drug; $x$-axis, dose of cocaine. cocaine administered $28.5 \mathrm{~h}$ after treatment with JHW007. Each cocaine point represents the average effect determined in five to six mice; for drug combinations, each point represents the effects of three to four mice. The error bars represent $+1 \mathrm{SEM}$.

have previously demonstrated that JHW007 has a high selectivity for the DAT relative to other monoamine transporters (Agoston et al., 1997) and have also evaluated the binding of JHW007 to other targets (Katz et al., 2004). Among the binding sites examined, JHW007 had a high affinity for $\sigma$-binding sites, and actions at these sites have been noted to influence the effects of cocaine (Menkel et al., 1991). Although the effects of $\sigma$ ligands are generally not as profound as those presently obtained with JHW007 (Katz et al., 2003), the possibility that antagonism of the behavioral effects of cocaine by JHW007 was attributable to actions at $\sigma$ receptors deserves further examination. JHW007 also has affinity for H1 histamine receptors, although actions at these sites do not appear to alter the behavioral effects of cocaine (Campbell et al., 2002).

It has been suggested that compounds with potential as therapeutic agents in the treatment of cocaine abuse might be found among those with a relatively high ratio of potency for the inhibition of DA transport and DAT affinity. Using this strategy, Simoni et al. (1993) examined a 7-methoxylated tropane analog that exhibited an approximate fourfold separation of these effects and produced a two-fold antagonism of the inhibition of DA uptake produced by cocaine. Subsequent studies have identified compounds with ratio values of $\sim 1.0$ that attenuated the increases in locomotor activity produced by cocaine (Zhao et al., 2000). Other compounds have been identified that had a ratio value $>1$, but without cocaineantagonist effects (Wang et al., 2000; Xu et al., 2002). Along similar lines, the DA uptake inhibitor GBR 12909 antagonized the increase in extracellular DA concentration after administration of cocaine (Rothman et al., 1991) and produced selective decreases in selfadministration of cocaine (Glowa et al., 1995). Although there are many differences among the results of all of these studies, a general conclusion is that not all DA uptake inhibitors produce effects identical to those of cocaine and that, under certain conditions, antagonist effects may be obtained.

The ratio of the $\mathrm{IC}_{50}$ value of JHW007 for the inhibition of DA uptake and its in vitro affinity for the DAT is 1.06 . This finding is consistent with the literature summarized above that suggests that 
antagonist effects of DA uptake inhibitors are not derived from differential activity within these assays. Nonetheless, the antagonism of cocaine by JHW007 and previous findings that not all DA uptake inhibitors produce effects identical to those of cocaine suggest that the DAT can function more like a receptor, at which compounds can have varying degrees of effectiveness. However, a second-messenger signaling system similar to that observed for G-protein-coupled receptors is not likely involved, and the molecular events responsible for variations in transduction of binding events to pharmacological actions remain to be determined.

In summary, JHW007 is a novel drug that has high affinity and selectivity for the DAT in vitro (Agoston et al., 1997; Katz et al., 2004). It passes the blood-brain barrier and readily penetrates the brain (Raje et al., 2003), slowly achieving significant levels of DAT occupancy without appreciable cocaine-like stimulant or subjective effects. Most importantly, JHW007 antagonizes the locomotor stimulant and subjective effects of cocaine. The present results in conjunction with others suggest that the rate of DAT occupancy is an important component of cocaine-like actions and potential for abuse. Furthermore, this study suggests in vivo association as a critical feature contributing to the effects of DAT ligands and suggests that JHW007 has the attributes necessary to serve as a lead candidate for the treatment of cocaine abuse.

\section{References}

Agoston GE, Wu JH, Izenwasser S, George C, Katz J, Kline RH, Newman AH (1997) Novel N-substituted $3 \alpha$-[bis( $4^{\prime}$-fluorophenyl)methoxy] tropane analogues: selective ligands for the dopamine transporter. J Med Chem 40:4329-4339.

Bergman J, Madras BK, Johnson SE, Spealman RD (1989) Effects of cocaine and related drugs in nonhuman primates. III. Self-administration by squirrel monkeys. J Pharmacol Exp Ther 251:150-155.

Blakely RD, Bauman AL (2000) Biogenic amine transporters: regulation in flux. Curr Opin Neurobiol 10:328-336.

Campbell VC, Kopajtic TA, Newman AH, Katz JL (2002) Evaluation of interactions between histamine $\mathrm{H} 1$ antagonist and cocaine effects as a mechanism for the decreased cocaine-like effects of benztropine analogs. Soc Neurosci Abstr 28:806.11.

Cline EJ, Scheffel U, Boja JW, Carroll FI, Katz JL, Kuhar MJ (1992) Behavioral effects of novel cocaine analogs: a comparison with in vivo receptor binding potency. J Pharmacol Exp Ther 260:1174-1179.

Gatley SJ, Volkow ND, Gifford AN, Fowler JS, Dewey SL, Ding YS, Logan J (1999) Dopamine-transporter occupancy after intravenous doses of cocaine and methylphenidate in mice and humans. Psychopharmacology 146:93-100.

Giros B, Jaber M, Jones SR, Wightman RM, Caron MG (1996) Hyperlocomotion and indifference to cocaine and amphetamine in mice lacking the dopamine transporter. Nature 379:606-612.

Glowa JR, Wojnicki FHE, Matecka D, Bacher JD, Mansbach RS, Balster RL, Rice KC (1995) Effects of dopamine reuptake inhibitors on food- and cocaine-maintained responding: I. Dependence on unit dose of cocaine. Exp Clin Psychopharmacol 3:219-231.

Goldner EM, Hsu L, Waraich P, Somers JM (2002) Prevalence and incidence studies of schizophrenic disorders: a systematic review of the literature. Can J Psychiatry 47:833-843.

Javitch JA, Blaustein RO, Snyder SH (1984) $\left[{ }^{3} \mathrm{H}\right]$ Mazindol binding associated with neuronal dopamine and norepinephrine uptake sites. Mol Pharmacol 26:35-44.

Katz JL, Izenwasser S, Kline RH, Allen AC, Newman AH (1999) Novel $3 \alpha$ diphenylmethoxytropane analogs: selective dopamine uptake inhibitors with behavioral effects distinct from those of cocaine. J Pharmacol Exp Ther 288:302-315.

Katz JL, Agoston GE, Alling KL, Kline RH, Forster MJ, Woolverton WL, Kopajtic TA, Newman AH (2001) Dopamine transporter binding without cocaine-like behavioral effects: synthesis and evaluation of benztropine analogs alone and in combination with cocaine in rodents. Psychopharmacology 154:362-374.

Katz JL, Libby TA, Kopajtic T, Husbands SM, Newman AH (2003) Behav- ioral effects of rimcazole analogues alone and in combination with cocaine. Eur J Pharmacol 468:109-119.

Katz JL, Kopajtic TA, Agoston GE, Newman AH (2004) Effects of $\mathrm{N}$-substituted analogs of benztropine: diminished cocaine-like effects in dopamine transporter ligands. J Pharmacol Exp Ther 309:650-660.

Kuhar MJ, Ritz MC, Boja JW (1991) The dopamine hypothesis of the reinforcing properties of cocaine. Trends Neurosci 14:299-302.

Madras BK, Fahey MA, Bergman J, Canfield DR, Spealman RD (1989) Effects of cocaine and related drugs in nonhuman primates. I. $\left[{ }^{3} \mathrm{H}\right]$ cocaine binding sites in caudate-putamen. J Pharmacol Exp Ther 251:131-141.

Menkel M, Terry P, Pontecorvo M, Katz JL, Witkin JM (1991) Selective sigma ligands block stimulant effects of cocaine. Eur J Pharmacol 201:251-252.

Newman AH, Kline RH, Allen AC, Izenwasser S, George C, Katz JL (1995) Novel $4^{\prime}$-substituted and $4^{\prime}, 4^{\prime \prime}$-disubstituted $3 \alpha$-(diphenylmethoxy)tropane analogs as potent and selective dopamine uptake inhibitors. J Med Chem 38:3933-3940.

ONDCP (Office of National Drug Control Policy) (2001) What America's users spend on illegal drugs, 1988-2000 (Publication no. NCJ 192334; www. whitehousedrugpolicy.gov/publications/pdf/american_users_spend_2002.pdf).

Raje S, Cao J, Newman AH, Gao H, Eddington ND (2003) Evaluation of the blood-brain barrier transport, population pharmacokinetics, and brain distribution of benztropine analogs and cocaine using in vitro and in vivo techniques. J Pharmacol Exp Ther 307:801-808.

Ritz MC, Lamb RJ, Goldberg SR, Kuhar MJ (1987) Cocaine receptors on dopamine transporters are related to self-administration of cocaine. Science 237:1219-1223.

Rothman RB, Mele A, Reid AA, Akunne HC, Greig N, Thurkauf A, de Costa BR, Rice KC, Pert A (1991) GBR12909 antagonizes the ability of cocaine to elevate extracellular levels of dopamine. Pharmacol Biochem Behav 40:387-397.

Rothman RB, Grieg N, Kim A, De Costa BR, Rice KC, Carroll FI, Pert A (1992) Cocaine and GBR12909 produce equivalent motoric responses at different occupancy of the dopamine transporter. Pharmacol Biochem Behav 43:1135-1142.

SAMSA (Substance Abuse and Mental Health Services Administration) (2002) Overview of findings from the 2002 National Survey on Drug Use and Health (Office of Applied Studies, NHSDA Series H_21, DHHS Publication no. SMA 03_3774; www.oas.samhsa.gov/NHSDA/2k2NSDUH/ 2k2SoFOverviewW.pdf).

Scahill L, Schwab-Stone M (2000) Epidemiology of ADHD in school-age children. Child Adolesc Psychiatr Clin N Am 9:541-555.

Scheffel U, Boja JW, Kuhar MJ (1989) Cocaine receptors: in vivo labeling with ${ }^{3} \mathrm{H}-(-)$ cocaine, ${ }^{3} \mathrm{H}-\mathrm{WIN} 35,065-2$, and ${ }^{3} \mathrm{H}-\mathrm{WIN} 35,428$. Synapse 4:390-392.

Simoni D, Stoelwinder J, Kozikowski AP, Johnson KM, Bergmann JS, Ball RG (1993) Methoxylation of cocaine reduces binding affinity and produces compounds of differential binding and dopamine uptake inhibitory activity: discovery of a weak cocaine "antagonist." J Med Chem 36:3975-3977.

Vaugeois JM, Bonnet JJ, Duterte-Boucher D, Costentin J (1993) In vivo occupancy of the striatal dopamine uptake complex by various inhibitors does not predict their effects on locomotion. Eur J Pharmacol 230:195-201.

Volkow ND, Fowler JS, Wang GJ (2002) Role of dopamine in drug reinforcement and addiction in humans: results from imaging studies. Behav Pharmacol 13:355-366.

Wang S, Sakamuri S, Enyedy IJ, Kozikowski AP, Deschaux O, Bandyopadhyay BC, Tella SR, Zaman WA, Johnson KM (2000) Discovery of a novel dopamine transporter inhibitor, 4-hydroxy-1-methyl-4-(4-methylphenyl)-3piperidyl 4-methylphenyl ketone, as a potential cocaine antagonist through 3D-database pharmacophore searching. Molecular modeling, structureactivity relationships, and behavioral pharmacological studies. J Med Chem 43:351-360.

Woolverton WL, Hecht GS, Agoston GE, Katz JL, Newman AH (2001) Further studies of the reinforcing effects of benztropine analogs in rhesus monkeys. Psychopharmacology 154:375-382.

Xu L, Izenwasser S, Katz JL, Kopajtic T, Klein-Stevens C, Zhu N, Lomenzo SA, Winfield L, Trudell ML (2002) Synthesis and biological evaluation of 2 -substituted $3 \beta$-tolyltropane derivatives at dopamine, serotonin, and norepinephrine transporters. J Med Chem 45:1203-1210.

Zhao L, Johnson KM, Zhang M, Flippen-Anderson J, Kozikowski AP (2000) Chemical synthesis and pharmacology of 6- and 7-hydroxylated 2-carbomethoxy-3-(p-tolyl)tropanes: antagonism of cocaine's locomotor stimulant effects. J Med Chem 43:3283-3294. 